\title{
LEPA: From Proteomics to Energy Conversion
}

\author{
Fernando Cortes-Salazar, Anne-Laure Gassner, Manuel A. Méndez, Mohammad Reza Pourhaghighi, \\ Liang Qiao, and Hubert H. Girault*
}

\begin{abstract}
This review article summarizes the different fields of research at the Laboratoire d'Electrochimie Physique et Analytique at the Ecole Polytechnique Fédérale de Lausanne. The research areas covered include charge transfer reactions at soft interfaces, bio-analytical microchips and electrophoretic methods, electrochemical ionization methods for mass spectrometry and Scanning Electrochemical Microscopy (SECM).
\end{abstract}

Keywords: Electrochemistry · ESI-MALDI · ITIES · OFFGEL · SECM

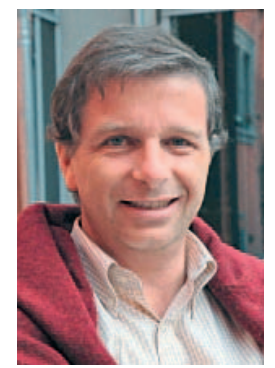

This year ISIC celebrates its 10th anniversary, and in 2012, the Laboratoire d'Electrochimie Physique et Analytique (LEPA) will celebrate its 20th birthday. This article is a good opportunity to look back and reflect on some achievements and to elaborate on some future perspectives.

The Chair of Electrochemistry in Lausanne was created in 1923 by Marcel Duboux, a chemist from the University of Lausanne, but also an oenology expert from a family of winemakers in Cully. At that time, conductivity and $\mathrm{pH}$ measurements were used to improve the quality of wine. Since then, electrochemistry has thrived in Lausanne, and LEPA was created in 1992 following the retirement of Prof. Pierre Lerch who had been the Director of the Institute of Electrochemistry and Radiochemistry (for some reasons radiochemistry had fallen out of favour at the time...).
LEPA is not a conventional electrochemistry laboratory as it is not active in the main themes of electrochemical research such as electrolysis, batteries, fuel cells or even solar cells. As a matter of fact, LEPA has specialised in 'electrochemistry without electrodes', in electrophoretic and ionisation methods and scanning electrochemical microscopy.

\section{Electrochemistry at Soft Interfaces}

LEPA has dedicated a major part of its effort to the study of polarised liquidliquid interfaces. Indeed, the Interface between Two Immiscible Electrolyte Solutions (ITIES) can be polarised if the aqueous phase contains hydrophilic electrolytes and the organic phase contains lipophilic electrolytes. On a metallic electrode such as mercury or platinum, the potential window is limited at positive potentials by the oxidation of the solvent or the anodic dissolution of the electrode and at negative potentials by the reduction of the solvent. In contrast, at the ITIES, the potential window is limited by the transfer of ions from the supporting electrolytes. Within this potential window different types of charge transfer reactions can be investigated namely:

- Ion transfer from one phase to the other; [1]

- Assisted ion transfer including interfacial acid-base reactions;

- Heterogeneous electron transfer reactions between an aqueous and an organic redox couples, such as the oxidation of ferrocene by ferricyanide; ${ }^{[2]}$

- Photo-induced electron transfer reactions. ${ }^{[3]}$

One question often asked is: Why study polarised liquid-liquid interfaces? From a physical chemistry standpoint, these interfaces have the main advantage compared to solid ones to be defect-free and hence measurements are highly reproducible. Indeed, a major challenge in classical electrochemistry is the control of the electrode surface, and this is a main reason why most physical electrochemistry over the last two decades has been carried out on single crystal electrodes where the surface properties can be verified by UHV spectroscopy techniques. Surface defects and traps are a major issue in photo-electrochemistry, which is not the case with soft interfaces. Furthermore, these interfaces when functionalised with a monolayer of phospholipids represent a very simple but yet extremely controlled biomimetic system to study reactions taking place at biomembranes. From an analytical standpoint, ion selective electrodes are based on a polymer electrolyte membrane and comprise two soft interfaces. Billions of ion activity measurements are carried out every year with ion selective electrodes.

Looking back, the main contributions of LEPA in that field have been the development of an electrochemical methodology for the measurements of the $\log P$ of ionised drug molecules, ${ }^{[4]}$ the development of spectro-electrochemical methods and more recently the study of interfacial functionalization by self-assembled catalysts and nano-objects. Last but not least, LEPA has been a productive training school and many LEPA members are now faculty members active in that field. In alphabetical order: P.-F. Brevet, University of Lyon (France), Z. Ding, University of West Ontario (Canada), R. Dryfe, University of Manchester (UK), D. Fermin, University of Bristol (UK), I. Hatay, University of Konya (Turkey), H. Jensen, University of Copenhagen (Denmark), H. J. Lee, Kyungpook National University (Korea), F. Li, Xi'an Jiaotong University (China), $\mathrm{H}$. Nagatani, Kanazawa University (Japan), 
Y. Shao, Peking University (China), B. $\mathrm{Su}$, Zhejiang University (China).

\section{Ionic Partition Diagram}

In a very fruitful collaboration with the group of Chimie Therapeutique (UNIL) led at the time by Prof. Bernard Testa and Pierre-Alain Carrupt, we have developed a voltammetry theory to analyse the transfer of ionised and ionisable drug molecules, and proposed the concept of ionic partition diagrams that are now widely used. ${ }^{[4]}$ These potential vs $\mathrm{pH}$ diagrams analogous to the Pourbaix diagrams in metal speciation provide a simple way to see how a drug molecule can partition for a given $\mathrm{pH}$ and a given polarisation, and hence predict its pharmacokinetic properties.

\section{Spectro-electrochemistry at ITIES}

With the long-term goal of developing a biomimetic model of artificial photosynthesis, we have developed over the years a rather comprehensive panel of methods such as:

Quasi-elastic light scattering to measure surface tension. Here, a laser beam passing through a liquid-liquid interface is quasi-elastically scattered by the interfacial capillary wave. This scattered light is further optically combined with diffracted light resulting from the passage of the beam through a diffraction grating. Finally, the acquired signal in the time domain is Fourier-transformed and converted into the frequency domain. The latter provides a power spectrum from which the frequency of the maximum observed in the power spectra, the capillary wave frequency, is directly linked to the interfacial tension, allowing its precise determination. ${ }^{[5]}$

Total internal reflection reflectance and fluorescence voltammetry to study specifically the transfer of coloured and fluorescent ions or to follow by UV-Vis the products of interfacial charge transfer reactions. ${ }^{[6]}$

Surface Second Harmonic generation at a polarised interface, ${ }^{[7]}$ for example to study the protonation of interfacial molecules as a function of the interface polarisation as a way to measure the surface $\mathrm{pH}$. Light polarization modulated reflectance is also a technique of great value for characterizing the self-assembly of molecules, e.g. metalloporphyrins at the interface. ${ }^{[8]}$

Photocurrent spectroscopy has been used to measure the interfacial quenching of an excited dye molecule in one phase by a redox quencher in the adjacent phase. Also, intensity modulated photocurrent spectroscopy was adapted to measure the kinetics of photo-induced electron transfer reactions.

Along with the development of a wide variety of experimental techniques for the characterization of interfacial reactions, as those aforementioned, great efforts have also been directed towards their theoretical description. Some of the most representative examples are facilitated ion-transfer, ${ }^{[9]}$ potential-dependent adsorption ${ }^{[10]}$ and heterogeneous photo-induced electron-transfer.[11]

\section{ITIES Functionalization}

Having developed a range of methodologies, we started to functionalise the interface in order to investigate interfacial reactivity. ${ }^{[12]}$ In a first approach, amphiphilic molecules such as phospholipids were used to mimic a biological membrane, and for example to study lipidpeptide interactions as a function of the interfacial polarisation. ${ }^{[13]}$ Adsorption at polarised liquid-liquid interfaces can lead to the formation of aggregates, ${ }^{[5]}$ and we have shown that one can use this property to self-assemble molecular catalysts. ${ }^{[14]}$ Very recently, we have shown that tetrathiafulvalene can form tetramers at the interface able to reduce oxygen to water through a four-electron reduction pathway.

Increasing attention has been put into the functionalization of the ITIES with the aim of producing hydrogen or reducing $\mathrm{CO}_{2}$, as alternative sources of energy.

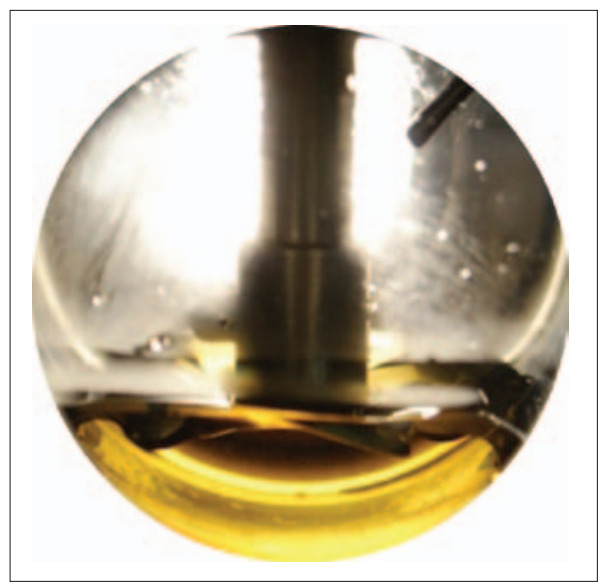

Fig. 1. Water-supercritical $\mathrm{CO}_{2}$ interface. Pressure $=80$ bars, the aqueous phase contains bromophenol blue.
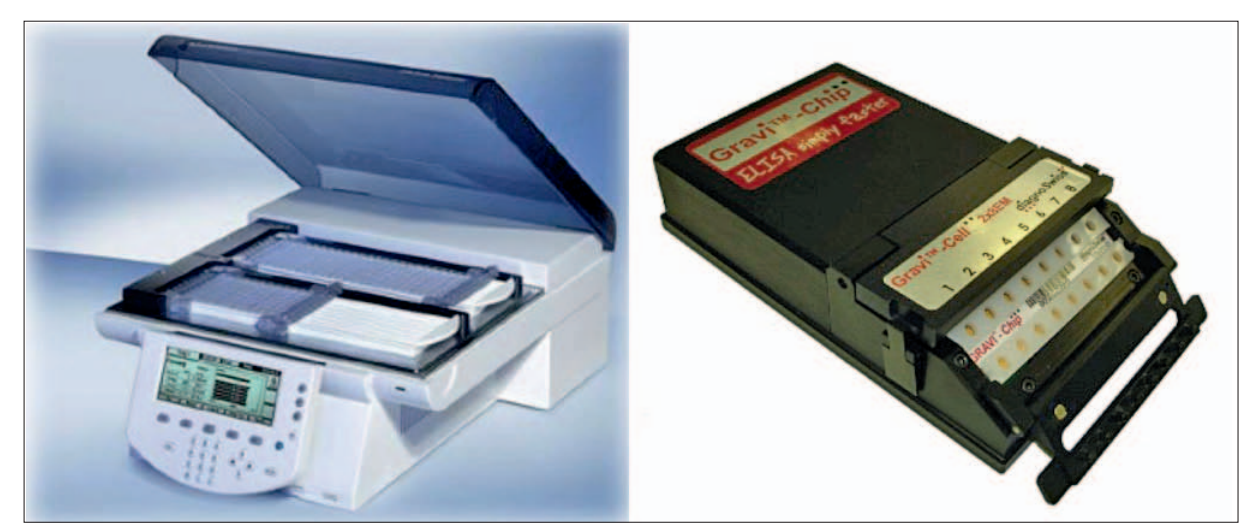

Fig. 2. Off-gel electrophoresis apparatus and electrochemical immuno-assay kit.
In this sense, hydrogen evolution has been observed for different metallocenes.[15] Furthermore, water-supercritical $\mathrm{CO}_{2}$ interfaces are under study, as a new kind of promising platform for carrying out the $\mathrm{CO}_{2}$ reduction reaction (see Fig. 1). [16]

Another way to functionalize the interface is to adsorb nanoparticles. ${ }^{[17]}$ For example, it is possible to form metallic gold mirrors at the ITIES by adsorbing gold nanoparticles. We have shown that by controlling the capping ligands and the interfacial polarisation, it is possible to make on-off mirrors at soft interfaces. These gold films can be used to enhance photo-electron transfer reactions when longitudinal surface plasmon resonance is established. [18]

\section{Microchips and Electrophoresis}

Since its creation, LEPA has used laser photoablation to produce polymer chips. Because microchannels made by this approach have oxidised charged walls, a very simple way to drive the microfluidics is to use electro-osmotic flow and electrophoresis has been shown to provide a very efficient separation method in these microstructures. This work on microchip fabrication has led to the creation of the spin-off company DiagnoSwiss that has been very active in the development of immunoassay chips (Fig. 2).

\section{Off-gel Electrophoresis}

Amongst all the analytical developments achieved over the last two decades, LEPA is certainly well-known for having conceived and developed the concept of off-gel electrophoresis (OGE), which is now commercialized by Agilent Technologies. Nowadays, OGE is used by most proteomic laboratories for highresolution fractionation of peptides and proteins at the micropreparative scale. ${ }^{[19]}$ This simple concept has proved to be very efficient, and it circumvents the problems of sample loading encountered in classical gel isoelectric focusing. OGE unique fea- 
tures facilitate integration of OGE into any proteomics workflow as it has been already used as the first separation dimension hyphenated to LC-MS/MS[20] and CZE.[21]

To develop highly sensitive methodologies for proteomics studies based on capillary zone electrophoresis (CZE), electrokinetic supercharging (EKS) has been integrated in CZE for low concentration peptide analysis. ${ }^{[22]}$ Furthermore, an automated iontophoretic fraction collection interface was developed for coupling CZE with matrix-assisted laser desorption/ ionisation mass spectrometry (MALDIMS). ${ }^{[23]}$ This fraction collection approach is based on electromigration and diffusion and it was demonstrated that the resolution of the separation was not altered by the spotting process.

Additionally, field-enhanced sample injection (FESI) was integrated as an online preconcentration strategy prior to $\mathrm{CZE}$ separation to develop a highly sensitive FESI-CZE-MALDI-MS methodology. [24]

Capillary electrophoresis was also used in conjunction with magnetic beads to carry out immunoassays. These beads, captured inside the capillary by permanent magnets placed on both sides enable a selective extraction of the analyte(s) of interest and its quantification as was demonstrated for beta-lactoglobulin in milk and total $\mathrm{IgE}$ in serum. ${ }^{[25,26]}$ LEPA has also been active in studying the magnetic aspects of magnetic beads trapping ${ }^{[27]}$ and in developing new systems to increase the magnetic force and the number of beads trapped.[28,29]

\section{Electrochemical Ionisation Methods for Mass Spectrometry}

Over the last decade, LEPA has conducted a research program aimed at exploring the electrochemical aspects of ionisation methods for mass spectrometry.

\section{Electrospray Ionisation}

Electrospray ionisation (ESI) mass spectrometry (MS) is widely used in bioanalytical research and proteomic studies. LEPA focused mainly on the electrochemical aspects of the ionisation and has developed many functionalized polymer microchip electrospray emitters. Electrospray for mass spectrometry was introduced in the 1980s to produce ions from large biomolecules. During ESI, a high voltage is applied between a solution flowing through a capillary and the mass spectrometer producing a fine mist of charged droplets to form gas-phase ions. According to the voltage polarity, either positive ions or negative ions can be extracted into the mass spectrometer for analysis. ${ }^{[30]}$

From an electrochemical standpoint, electrospray can be viewed as a two-elec-

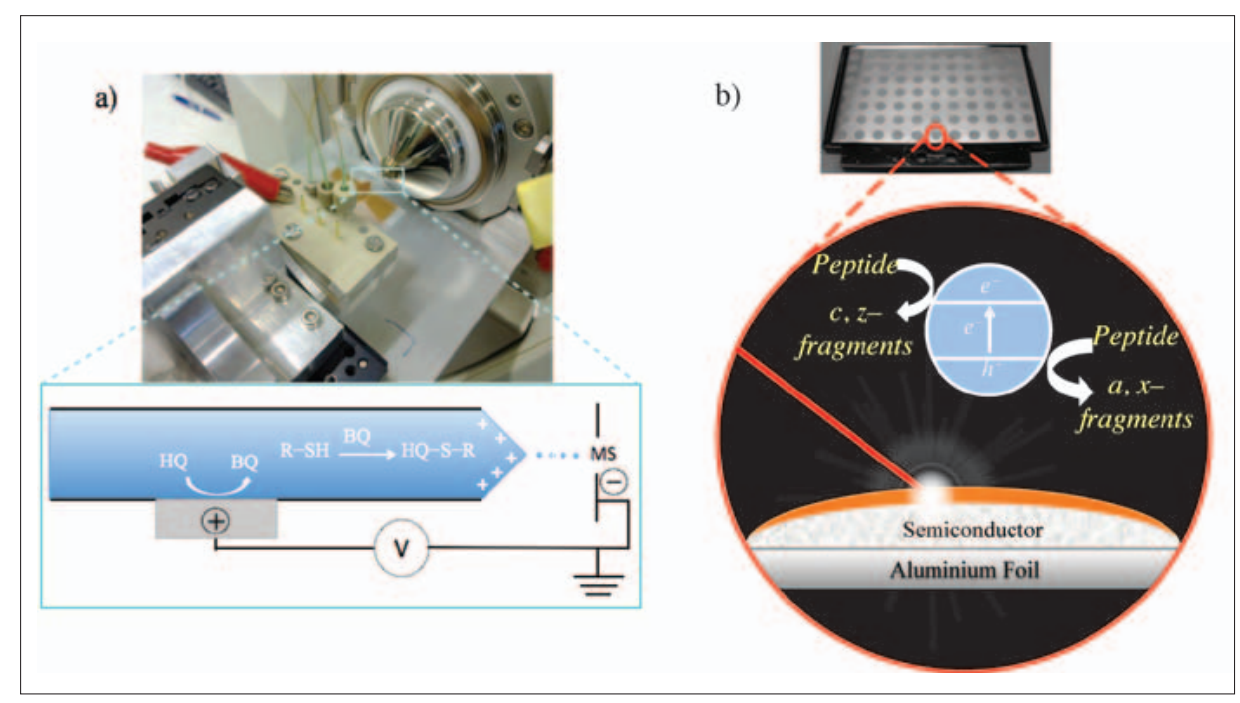

Fig. 3. a) Microchip works as emitter for nano-ESI, and the schematic illustration of the ESI online oxidation of hydroquinone for the tagging of thiol group containing peptides. HQ: hydroquinone, $\mathrm{BQ}$ : benzoquinone, R-SH: thiol containing peptide. b) MALDI target plate covered with aluminium foil printed with $\mathrm{TiO}_{2}$ semiconductor, and the schematic illustration of the laser desorption ionisation in-source photo-electro reactions of peptide reductive and oxidative fragmentations.

trode electrochemical cell. When the current is generated under an applied voltage, electrochemical reactions can occur both at the metallsolution interface and at the ion detector. ${ }^{[30]}$ Based on this principle, LEPA has investigated on-line electrochemical reactions during the ESI process with direct MS identification. For example, when hydroquinone is added in a solution of peptides/proteins, benzoquinone can be generated online at the surface of the electrode contacting the sample solution, which can further react with the thiol group on cysteine residues via Michael addition to tag the peptides containing cysteines (Fig. 3). ${ }^{[31]}$ With this strategy, the number of cysteines in a peptide can be obtained from a single mass spectrum, which can be helpful to constrain database query and to facilitate protein identification. When a sacrificial metallic electrode is used to induce the ESI, metallic ions, such as $\mathrm{Cu}^{+}$, can be generated if the electrode is an anode to tag the peptides. ${ }^{[32]}$ With this principle, combining between $\mathrm{Cu}^{+/ 2+}$ and $\beta$-amyloid peptide was studied, which is quite important for neurodegenerative disorders. ${ }^{[33]}$ More recently, we have used microchips to study the oxidation of biomolecules to develop an electrochemical redoxomics strategy.

LEPA is also interested in the hyphenation of microfluidic devices with ESI-MS, e.g. to fabricate microchips working as both microreactor and emitter for ESI. By using a dual-channel microchip, phosphopeptides can be tagged online in the Taylor cone of ESI. ${ }^{[32]}$ When a multi-channel microchip is used, tyrosine nitration can be performed online by introducing various reactants through several micro-channels, and the nitrated peptides can be characterized by MS. Droplets of oil and water can also form in the microchannel to perform online liquid-liquid interface reactions as well as sample extractions.

\section{Matrix-Assisted Laser Desorption/ Ionisation}

LEPA has also conducted a research program to unravel the electrochemical aspects of MALDI-MS. As a major soft ionisation strategy used in bio-analytical studies, the MALDI technology first developed in the eighties has undergone much progress during the last 20 years. In MALDI, the samples are usually mixed with matrices, small organic molecules that can absorb laser energy and accept/donate protons, and deposited on a metallic substrate. After drying the sample completely in ambient conditions, the substance is usually put in a vacuum to perform the laser desorption ionisation. Under laser irradiation, the light energy can be absorbed by the matrices to finally induce the desorption of the sample molecules or ions buried inside the matrices. In the plume generated from the laser shooting, many species, such as ions, electrons, radicals and molecules react to generate the final ions to be extracted and analyzed by mass spectrometer.[30,34] Based on such a principle, the studies in LEPA about MALDI-MS are mainly focused on the electro-photochemical reactions happening on the plate during the laser desorption ionisation.

To make the MALDI in-source reactions controllable, semiconductor materials were employed to cover the metallic plates. Under light irradiation, the electrons in the valence band of semiconductors can be excited to the conduction band to form hole-electron pairs. The oxidative holes in the valence band and the reduc- 
tive electrons in the conduction band can react with the samples present on the surface of semiconductors to induce in-source redox reactions, and the reaction products can be directly analyzed by MS spectrometer. With this principle, peptide in-source oxidative fragmentation, disulfide bond in-source reduction and cysteine in-source tagging were realized to facilitate proteomic analyses. [35-39]

Another investigation involving MALDI-MS in LEPA is affinity mass spectrometry for phospho-peptides/proteins analysis. Modifying the MALDI target plate with nanomaterials, such as $\mathrm{TiO}_{2}$ or $\mathrm{Al}_{2} \mathrm{O}_{3},{ }^{[40,41]}$ which have specific affinity to the phosphorylated peptides/proteins, phospho-samples can be in situ isolated from complex backgrounds and enriched on the MALDI plate for MS analysis. ${ }^{[40]}$ Disposable aluminium foils printed with $\mathrm{TiO}_{2}$ spots were further developed as substrates for phospho-sample in situ enrichment. ${ }^{[42]}$ Furthermore, LEPA is also interested in protein fast digestion on the target plate of MALDI with the assistance of porous silica. ${ }^{[43,44]}$

\section{Scanning Electrochemical Microscopy}

LEPA has also pioneered the concept of soft stylus probes for Scanning Electrochemical Microscopy (SECM). ${ }^{[45}$ SECM is a scanning probe microscope technique where a microelectrode is used above a substrate to carry out a redox reaction to interact with the substrate. As the probe approaches the sample surface, either the substrate is inert and the supply of reactants to the electrode and hence the current decreases (negative feedback) or the substrate is (electro)chemical active and the products of the microelectrode reaction can be cycled thereby providing a current increase (positive feedback). Therefore, SECM can be used to map the reactivity of the substrate and to study the kinetics of mass transport and charge transfer processes occurring at different interfaces (e.g. solid-liquid, liquid-liquid and gas-liquid). The developed soft stylus probes are microfabricated in a polymer substrate that contains an electrically conductive track that is exposed to act as the recording microelectrode. In contrast to classical SECM measurements where the probe is scanned above the substrate paying special attention to not destroying the probe or the sample upon contact, soft probes are scanned in contact mode maintaining an almost constant working distance without damaging the probe or samples that are harder than the probe. ${ }^{[45]}$

Additionally, by multiplexing the concept of soft stylus probe from one to eight

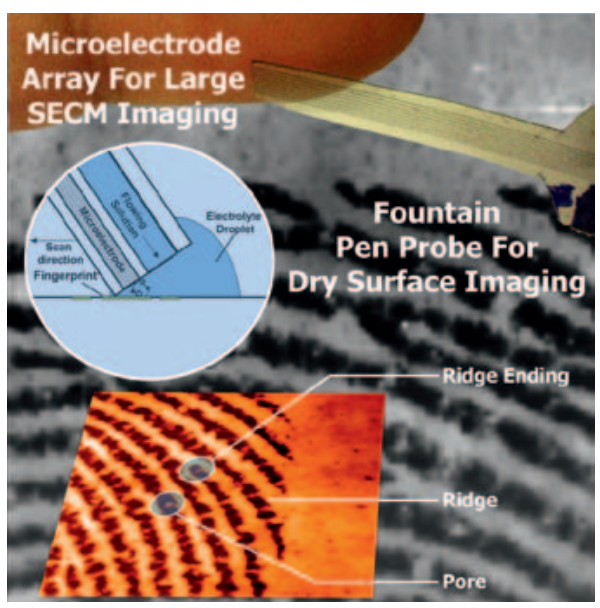

Fig. 4. Latent fingerprint imaging using a soft microelectrode array or fountain pen probe.

microelectrodes we are able to scan in less time over very large sample areas $e . g . \mathrm{cm}^{2}$ to image for example human fingerprints on a wide range of objects and by using different methodologies (Fig. 4). ${ }^{[46-48]}$

We then developed the concept of fountain pen probes, which are soft stylus tips with an integrated open microchannel to supply an electrolyte solution to form a moving droplet between the probe and the surface. ${ }^{49]}$ With this fountain pen probe, we can read and write on previously dry objects, which is very advantageous for samples that cannot be immersed in an electrochemical cell such as when imaging human fingerprints on a bank note.

Finally, we have developed the concept of push-pull soft tips, which are basically fountain pen probes with an additional open microchannel to aspirate the electrolyte dispensed through the other channel.[50] In this way, we can collect the solution that has contacted the substrate and use it for further analysis for example by HPLC or mass spectrometry. Moreover, sample contamination is avoided. A goal here would be to image a human fingerprint and collect any associated chemical information such as the presence of drugs of abuse.

The main objective of LEPA in this field is to develop an electrochemical scanner to image the chemical reactivity of biological tissues and a high-throughput read-write scanner for electrochemical machining at the micron resolution.

The future of LEPA is bright. Indeed, "Quand on aime, on a toujours 20 ans..."

Received: July 11, 2011

[1] A. J. Olaya, M. A. Méndez, F. Cortes-Salazar, H. H. Girault, J. Electroanal. Chem. 2010, 644, 60.

[2] Z. Ding, D. J. Fermín, P.-F. Brevet, H. H. Girault, J. Electroanal. Chem. 1998, 458, 139.

[3] N. Eugster, D. J. Fermín, H. H. Girault, J. Am. Chem. Soc. 2003, 125, 4862.
[4] V. Gobry, S. Ulmeanu, F. Reymond, G. Bouchard, P.-A. Carrupt, B. Testa, H. H. Girault, J. Am. Chem. Soc. 2001, 123, 10684.

[5] H. Nagatani, Z. Samec, P. F. Brevet, D. J. Fermín, H. H. Girault, J. Phys. Chem. B 2003, 107, 786.

[6] H. Nagatani, R. A. Iglesias, D. J. Fermín, P.-F. Brevet, H. H. Girault, J. Phys. Chem. B 2000, 104, 6869.

[7] A. Piron, P. F. Brevet, H. H. Girault, J. Electroanal. Chem. 2000, 483, 29.

[8] N. Eugster, K. Sreenivasan, B. Su, H. Girault, Langmuir 2006, 22, 1112.

[9] F. Reymond, P. Carrupt, H. Girault, J. Electroanal. Chem. 1998, 449, 49.

[10] M. A. Méndez, B. Su, H. H. Girault, J. Electroanal. Chem. 2009, 634, 82.

[11] Z. Samec, N. Eugster, D. J. Fermín, H. H. Girault J. Electroanal. Chem. 2005, 577, 323.

[12] M. Mendez, A. Olaya, N. Younan, M. Hojeij, H. Girault, Phys. Chem. Chem. Phys. 2010, 12 15163.

[13] M. A. Méndez, M. Prudent, B. Su, H. H. Girault, Anal. Chem. 2008, 80, 9499

[14] D. Schaming, I. Hatay, F. Cortes-Salazar, A Olaya, M. A. Méndez, P. Ge, H. Deng, P. Voyame, Z. Nayemi, H. H. Girault, Chimia 2011, 65, 356.

[15] I. Hatay, B. Su, F. Li, R. Partovi-Nia, H. Vrubel, X. Hu, M. Ersoz, H. H. Girault, Angew. Chem. Int. Ed. 2009, 48, 5139.

[16] M. A. Méndez, P. Voyame, H. H. Girault, Angew. Chem. Int. Ed. 2011, Accepted.

[17] B. Su, J.-P. Abid, D. J. Fermìn, H. H. Girault, H Hoffmannova, P. Krtil, Z. Samec, J. Am. Chem. Soc. 2004, 126, 915.

[18] M. Hojeij, N. Younan, L. Ribeaucourt, H. H. Girault, Nanoscale 2010, 2, 1665

[19] A. Ros, M. Faupel, H. Mees, J. Van Oostrum, R. Ferrigno, F. Reymond, P. Michel, J. S. Rossier, H. H. Girault, Proteomics 2002, 2, 151.

[20] P. E. Michel, D. Crettaz, P. Morier, M. Heller, D. Gallot, J. D. Tissot, F. Reymond, J. S. Rossier, Electrophoresis 2006, 27, 1169.

[21] J. M. Busnel, N. Lion, H. H. Girault, Anal. Chem 2007, 79, 5949

[22] J. M. Busnel, N. Lion, H. H. Girault, Electrophoresis 2008, 29, 1565.

[23] J. M. Busnel, J. Josserand, N. Lion, H. H. Girault Anal. Chem. 2009, 81, 3867.

[24] M. R. Pourhaghighi, J.-M. Busnel, H. H. Girault, Electrophoresis 2011, 32, 1795.

[25] H. X. Chen, J. M. Busnel, A. L. Gassner, G. Peltre, X. X. Zhang, H. H. Girault, Electrophoresis 2008, $29,3414$.

[26] H. X. Chen, J. M. Busnel, G. Peltre, X. X. Zhang, H. H. Girault, Anal. Chem. 2008, 80, 9583.

[27] A. L. Gassner, M. Abonnenc, H. X. Chen, J. Morandini, J. Josserand, J. S. Rossier, J. M Busnel, H. H. Girault, Lab Chip 2009, 9, 2356.

[28] A. L. Gassner, J. Morandini, J. Josserand, H. H. Girault, Anal. Meth. 2011, 3, 614.

[29] B. Teste, F. Malloggi, A. L. Gassner, T. Georgelin, J. M. Siaugue, A. Varenne, H. Girault, S Descroix, Lab on a Chip 2011, 11, 833.

[30] M. Abonnenc, L. A. Qiao, B. H. Liu, H. H. Girault, in 'Annual Review of Analytical Chemistry', Vol 3, Vol. 3, Annual Reviews, Palo Alto, 2010, pp. 231.

[31] L. Dayon, C. Roussel, H. H. Girault, Chimia 2004, 58, 204.

[32] M. Prudent, M. A. Mendez, C. Roussel, B. Su, N Lion, J. S. Rossier, H. H. Girault, Chimia 2009, 63, 283.

[33] Y. Lu, M. Prudent, L. A. Qiao, M. A. Mendez, H H. Girault, Metallomics 2010, 2, 474.

[34] H. Girault, B. H. Liu, L. A. Qiao, H. Y. Bi, M Prudent, N. Lion, M. Abonnenc, Eur. J. Mass Spectrom. 2010, 16, 341.

[35] L. Qiao, H. Y. Bi, J. M. Busnel, B. H. Liu, H. H. Girault, Chem. Commun. 2008, 6357.

[36] L. Qiao, H. Y. Bi, J. M. Busnel, J. Waser, P. Y. Yang, H. H. Girault, B. H. Liu, Chem. Eur. J. 2009, 15, 6711. 
[37] L. Qiao, C. Roussel, J. J. Wan, J. Kong, P. Y. Yang, H. H. Girault, B. H. Liu, Angew. Chem. Int. Ed. 2008, 47, 2646.

[38] L. A. Qiao, B. H. Liu, H. H. Girault, Nanomedicine 2010, 5, 1641.

[39] L. Qiao, F. Z. Su, H. Y. Bi, H. H. Girault, B. H. Liu, Proteomics 2011, DOI 10.1002/ pmic.201100208.

[40] L. Qiao, C. Roussel, J. J. Wan, P. Y. Yang, H. H. Girault, B. H. Liu, J. Proteome Res. 2007, 6, 4763.

[41] L. A. Qiao, H. Y. Bi, J. M. Busnel, M. Hojeij, M. Mendez, B. H. Liu, H. H. Girault, Chem. Sci. 2010, $1,374$.

[42] H. Y. Bi, L. Qiao, J. M. Busnel, V. Devaud, B. H. Liu, H. H. Girault, Anal. Chem. 2009, 81, 1177.

[43] H. Y. Bi, L. Qiao, J. M. Busnel, B. H. Liu, H. H. Girault, J. Proteome Res. 2009, 8, 4685.

[44] K. Qian, J. J. Wan, L. Qiao, X. D. Huang, J. W. Tang, Y. H. Wang, J. L. Kong, P. Y. Yang, C. Z. Yu, B. H. Liu, Anal. Chem. 2009, 81, 5749.
[45] F. Cortés-Salazar, M. Traeuble, F. Li, J.-M. Busnel, A. Gassner, M. Hojeij, G. Wittstock, H. H. Girault, Anal. Chem. 2009, 81, 6889.

[46] F. Cortés-Salazar, D. Momotenko, H. H Girault, A. Lesch, G. Wittstock, Anal. Chem. 2011, 83, 1493.

[47] F. Cortés-Salazar, D. Momotenko, A. Lesch, G. Wittstock, H. H. Girault, Anal. Chem. 2010, 82, 10037.

[48] F. Cortés-Salazar, M. Zhang, A. Becue, J.M. Busnel, M. Prudent, C. Champood, H. H. Girault, Chimia 2009, 63, 580.

[49] F. Cortés-Salazar, A. Lesch, D. Momotenko, J.M. Busnel, G. Wittstock, H. H. Girault, Anal. Meth. 2010, 2, 817.

[50] D. Momotenko, F. Cortés-Salazar, A. Lesch, G. Wittstock, H. H. Girault, Anal. Chem. 2011, submitted. 